\title{
DNA Strands from Denatured Duplexes are Translocated through Engineered Protein Nanopores at Alkaline pH
}

\author{
Giovanni Maglia, ${ }^{\dagger}$ Marsiyana Henricus, ${ }^{\dagger}$ Romain Wyss, ${ }^{\ddagger}$ Qiuhong $\mathrm{Li}^{\dagger}{ }^{\dagger}$ \\ Stephen Cheley, ${ }^{\dagger}$ and Hagan Bayley ${ }^{\dagger}$ \\ Department of Chemistry, University of Oxford, Oxford, OX1 3TA, United Kingdom, \\ and Institut des Sciences et Ingénierie Chimiques, Ecole Polytechnique Fédérale de \\ Lausanne, Lausanne, Switzerland
}

Received June 24, 2009; Revised Manuscript Received July 24, 2009

\begin{abstract}
Nanopores are under development for the detection of a variety of analytes and the investigation of chemical reactions at the single molecule level. In particular, the analysis of nucleic acid molecules is under intense investigation, including the development of systems for rapid, low-cost DNA sequencing. Here, we show that DNA can be translocated through an engineered $\alpha \mathrm{HL}$ protein pore at pH 11.7, a value at which dsDNA is denatured. Therefore, the $\alpha \mathrm{HL}$ pore is sufficiently stable to entertain the possibility of direct nanopore sequencing of genomic dsDNA samples, which are more readily obtained and handled than ssDNA.
\end{abstract}

Nanometer-sized pores have been used for molecular detection $^{1}$ and to investigate chemical reactions ${ }^{2}$ at the singlemolecule level, based on the observation that small changes in the current carried by ions through a nanopore reflect binding events or bond making and breaking. The analysis of nucleic acids has attracted attention following the finding that single-stranded DNA (ssDNA), but not double-stranded DNA (dsDNA), can be driven through the $\alpha$-hemolysin $(\alpha H L)$ protein pore under an electrical potential. ${ }^{3}$ This work suggested the possibility of sequencing ssDNA as it is translocated $;{ }^{3}$ the ionic current would be modulated to a different extent by each base as it passed a recognition site within the lumen of the pore. ${ }^{4,5}$

Several recent studies have suggested that it may be possible to distinguish DNA bases in this way. Notably, Stoddart and co-workers showed that when ssDNA is immobilized within the $\alpha \mathrm{HL}$ pore, individual bases can be distinguished at specific sites within a DNA strand. ${ }^{6}$ Therefore, if DNA strands could be fed through $\alpha \mathrm{HL}$ pores in a highly parallel format ${ }^{4,5}$ at a slow enough rate for base identification, ${ }^{4,5}$ a viable means for rapid DNA sequencing would be achieved. Because the approach is reagent-free and requires no DNA amplification, the use of nanopores would dramatically reduce the cost of sequencing. ${ }^{4,5}$

Recent advances in fabrication technology have provided improved means to produce solid-state pores with diameters of a few nanometers. ${ }^{7,8}$ The dimensions of these pores can

\footnotetext{
${ }^{\dagger}$ University of Oxford.

* Ecole Polytechnique Fédérale de Lausanne.
}

be tuned and they can be employed under a wide range of conditions in a variety of solvents. ${ }^{9,10}$ The stability of nanopores in extreme environments is desirable for DNA analysis, including sequencing, because high temperatures, high $\mathrm{pH}$ and denaturants can be used to convert dsDNA to ssDNA, and to maintain ssDNA in a fully denatured form. However, synthetic pores have several drawbacks. For example, they display a large variability in conductance and exhibit significant current noise ${ }^{11-13}$ compared to the $\alpha \mathrm{HL}$ pore.

Protein pores, such as the $\alpha \mathrm{HL}$ pore, can be made reproducibly and modified by site-directed mutagenesis with atomic precision. Instability under extreme conditions is seen as a weakness of protein nanopores. ${ }^{89}$ But, we have already shown that the $\alpha \mathrm{HL}$ pore is stable at temperatures close to $100{ }^{\circ} \mathrm{C} .{ }^{14}$ In the present work, we address the stability of the $\alpha \mathrm{HL}$ pore under alkaline conditions. We show that DNA can be translocated through an engineered $\alpha \mathrm{HL}$ pore at $\mathrm{pH}$ 11.7 , a pH value at which genomic DNA is converted to the single-stranded form, ${ }^{15-17}$ because of ionization of $\mathrm{G}$ and $\mathrm{T}$ bases. ${ }^{18}$ Since nanopore DNA sequencing may require denaturing conditions for dsDNA on at least one side of the bilayer, this finding might be of practical value. High $\mathrm{pH}$ conditions might also be useful for other aspects of nanopore detection, including stochastic sensing, ${ }^{1}$ and in the investigation of single-molecule covalent chemistry. ${ }^{2}$

Results and Discussion. $\alpha H L$ Nanopores at High $\mathrm{pH}$. $\alpha \mathrm{HL}$ forms heptameric pores that consist of a barrel (or stem) domain and a cap domain (Figure 1a). The barrel forms a 


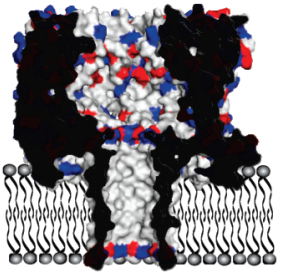

Lys de-protonated
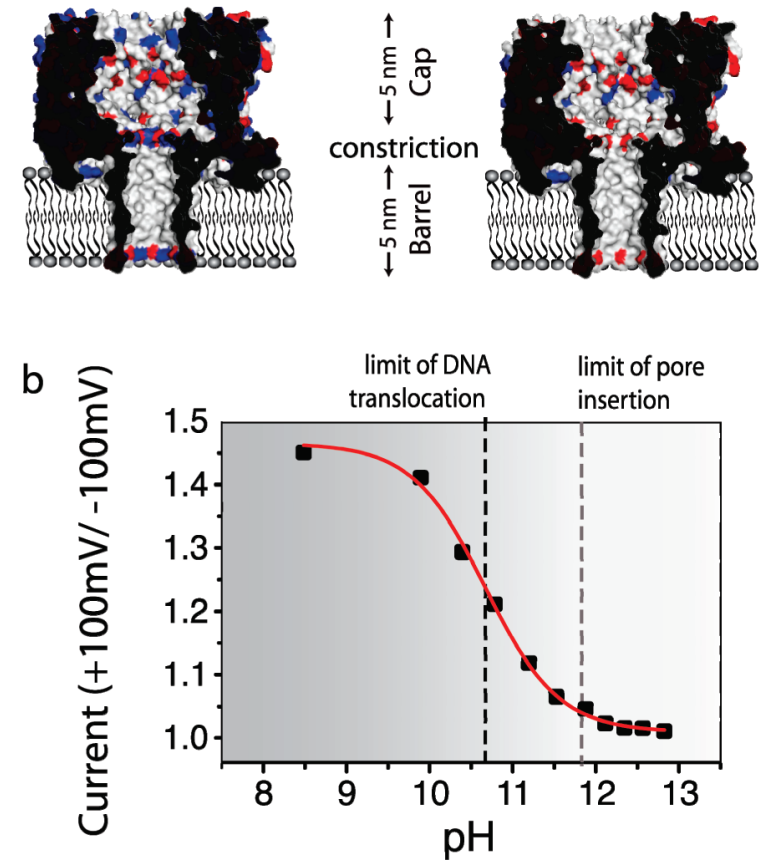

Figure 1. $\alpha H L$ nanopores at neutral and alkaline $\mathrm{pH}$. (a) Sections through the heptameric pores formed by WT $\alpha \mathrm{HL}$ (PDB: 7AHL), with Lys residues protonated (left) and deprotonated (right), rendered using PyMOL (v1.0, DeLano Scientific). Negatively charged amino acids are colored red, and positively charged amino acids blue. (b) Dependence of the current rectification (the conductance at $+100 \mathrm{mV}$ divided by the conductance at $-100 \mathrm{mV}$ ) on the $\mathrm{pH}$ of the solution for a single WT- $\alpha \mathrm{HL}$ pore reconstituted in a planar lipid bilayer. The red line is a sigmoidal fit to a typical data set. The mean midpoint was $\mathrm{pH} 10.7 \pm 0.1$ ( $n=4$ data sets). The black dashed line indicates the $\mathrm{pH}$ above which no ssDNA translocation is observed for WT $\alpha \mathrm{HL}$ in $1.0 \mathrm{M} \mathrm{KCl}$ and at +120 $\mathrm{mV}$ (Figure S4, Supporting Information). The gray dashed line indicates the $\mathrm{pH}$ above which the insertion of WT- $\alpha \mathrm{HL}$ heptamers $\left(\sim 1 \mu \mathrm{g} \mathrm{mL}^{-1}\right)$ is no longer observed. The buffer used was $10 \mathrm{mM}$ Tris.HCl, $10 \mathrm{mM}$ CAPS, $15 \mathrm{mM} \mathrm{K}$ phosphate, $1.0 \mathrm{M} \mathrm{KCl}, 100$ $\mu \mathrm{M}$ EDTA. The $\mathrm{pH}$ was adjusted to the desired values by adding small portions of $2.0 \mathrm{M} \mathrm{KOH}$ to the chambers.

roughly cylindrical water-filled channel spanning the lipid bilayer with an internal diameter of $\sim 2 \mathrm{~nm}$ and a length of $\sim 5 \mathrm{~nm}$. The internal vestibule within the cap is roughly spherical with a diameter of $\sim 4.5 \mathrm{~nm}$ (Figure 1a). The lumen of the wild-type (WT)- $\alpha \mathrm{HL}$ pore contains seven negatively charged residues (Asp-2, Asp-4, Asp-13, Glu-108, Glu-111, Asp-127 and Asp-227) and seven positively charged residues (Lys-8, Arg-56, Arg-104, Lys-110, Lys-131, Lys-147 and Lys-154) per protomer. Consequently, to a first approximation, the interior of the pore carries no overall charge at physiological $\mathrm{pH}$ (Figure 1a), while at alkaline $\mathrm{pH}(\mathrm{pH}$ $>10.5$ ), the lysine residues are deprotonated, and the interior is negatively charged, assuming that the $\mathrm{p} K_{\mathrm{a}}$ values of the amino acids in the lumen of the pore are not shifted from their expected values (Figure 1a).

Once inserted into a 1,2-diphytanoyl-sn-glycero-3-phosphocholine (DPhPC) lipid bilayer, we found the $\alpha \mathrm{HL}$ pore to be stable at alkaline $\mathrm{pH}$ values. The pore showed a stable unitary open-pore conductance at all $\mathrm{pH}$ values tested up to $\mathrm{pH} \sim 13$. However, the value of the unitary conductance changed with the $\mathrm{pH}$. At negative applied potentials, the conductance of the pore increased with the $\mathrm{pH}$. At positive applied potentials, the conductance first decreased and then increased as the $\mathrm{pH}$ was increased (Figure S1, Supporting Information). The rectification ratio for a single pore, expressed as the current at $+100 \mathrm{mV}$ divided by the current at $-100 \mathrm{mV}$, was therefore also $\mathrm{pH}$ dependent (Figure $1 \mathrm{~b}$ ). The data were fitted with a sigmoidal function with a midpoint at $\mathrm{pH} 10.7 \pm 0.1$.

While the pore remained open at alkaline $\mathrm{pH}$ values, the rate of insertion of preformed $\alpha \mathrm{HL}$ heptamers into the lipid bilayer decreased dramatically when the $\mathrm{pH}$ was higher than 11.0, and no insertion at all was observed when the $\mathrm{pH}$ was higher than 11.7 (Figure 1b).

Structural Studies. To investigate the effect of alkaline $\mathrm{pH}$ on the structure of $\alpha \mathrm{HL}$, WT- $\alpha \mathrm{HL}$ heptamers (1 mg $\mathrm{mL}^{-1}$ in $10 \mathrm{mM} \mathrm{Na}$ phosphate, $10 \mathrm{mM}$ CAPS, $10 \mathrm{mM}$ Tris. $\mathrm{HCl}, 150 \mathrm{mM} \mathrm{NaCl}$, containing $0.3 \% \mathrm{w} / \mathrm{v}$ SDS, at $\mathrm{pH}$ 8.0) were diluted to $100 \mu \mathrm{g} \mathrm{mL}^{-1}$ into the same buffer, which had been adjusted to various $\mathrm{pH}$ values with $1.0 \mathrm{M} \mathrm{NaOH}$ (from $\mathrm{pH} 8.0$ to $\mathrm{pH} 13.0$ ). The samples were incubated for $8 \mathrm{~h}$ and then loaded onto a $10 \%$ SDS-polyacrylamide gel, after the addition of loading buffer without heating. The gel was run at room temperature. WT- $\alpha$ HL heptamers maintained their quaternary structure at up to $\mathrm{pH} 12.5$, but at $\mathrm{pH}$ 13.0 the heptamers were converted to monomers (Figure 2a), in approximately one minute (data not shown). It is important to note that under these conditions $(0.3 \%$ SDS w/v and 150 $\mathrm{mM} \mathrm{NaCl}) \alpha H L$ may be less stable than in a DPhPC lipid bilayer, as breakdown of the heptamer was not observed in the latter case as judged by current recording. In a related case, heptamers in SDS solution broke down at $\sim 65{ }^{\circ} \mathrm{C}$, while they were stable in DPhPC bilayers at temperatures close to $100{ }^{\circ} \mathrm{C} .{ }^{14}$

The effect of $\mathrm{pH}$ on the structure of WT $\alpha \mathrm{HL}$ was investigated by fluorescence spectroscopy (Figures 2b, S2a, Supporting Information). In proteins containing tryptophan, the fluorescence emission maximum $\left(\lambda_{\max }{ }^{\mathrm{em}}\right)$ with excitation at 280 to $295 \mathrm{~nm}$, ranges from 308 to $355 \mathrm{~nm}^{19}$ depending on the environment of the tryptophan residues, with nonpolar environments having the most blue-shifted emission. The unfolding of a protein leads to a red shift in the emission to a $\lambda_{\max }{ }^{\mathrm{em}}$ value in the range 345 to $355 \mathrm{~nm}$ as buried tryptophans become more exposed to solvent. ${ }^{20,21}$ All eight tryptophans in the $\alpha \mathrm{HL}$ pore are in the cap domain of the protein; four are almost entirely buried within the hydrophobic core of the protein (Trp-80, Trp-167, Trp-265 and Trp-286), while the remaining four are at least partly solvent exposed (Trp-179, Trp-187, Trp-260 and Trp-274). ${ }^{22}$ The $\mathrm{pH}$ dependence of the $\lambda_{\max }{ }^{\mathrm{em}}$ of $\alpha \mathrm{HL}$ heptamers $\left(100 \mu \mathrm{g} \mathrm{mL} \mathrm{m}^{-1}\right.$ in $10 \mathrm{mM} \mathrm{Na}$ phosphate, $10 \mathrm{mM}$ CAPS, $10 \mathrm{mM}$ Tris. $\mathrm{HCl}$, $150 \mathrm{mM} \mathrm{NaCl}$, containing $0.3 \% \mathrm{w} / \mathrm{v}$ SDS) indicates that, up to $\mathrm{pH} 11.5$, the cap domain most likely has a native-like conformation, while at $\mathrm{pH} 12.0$ it has started to unfold (Figure 2b, S2a, Supporting Information). At $\mathrm{pH}$ 13.0, the fluorescence emission of the protein $\left(\lambda_{\max }{ }^{\mathrm{em}}=354 \mathrm{~nm}\right)$ is similar to that of $\mathrm{N}$-acetyltryptophanamide in solution $\left(\lambda_{\max }{ }^{\mathrm{em}}\right.$ $=358 \mathrm{~nm}$ ), indicating that, unless the fluorescence emission 


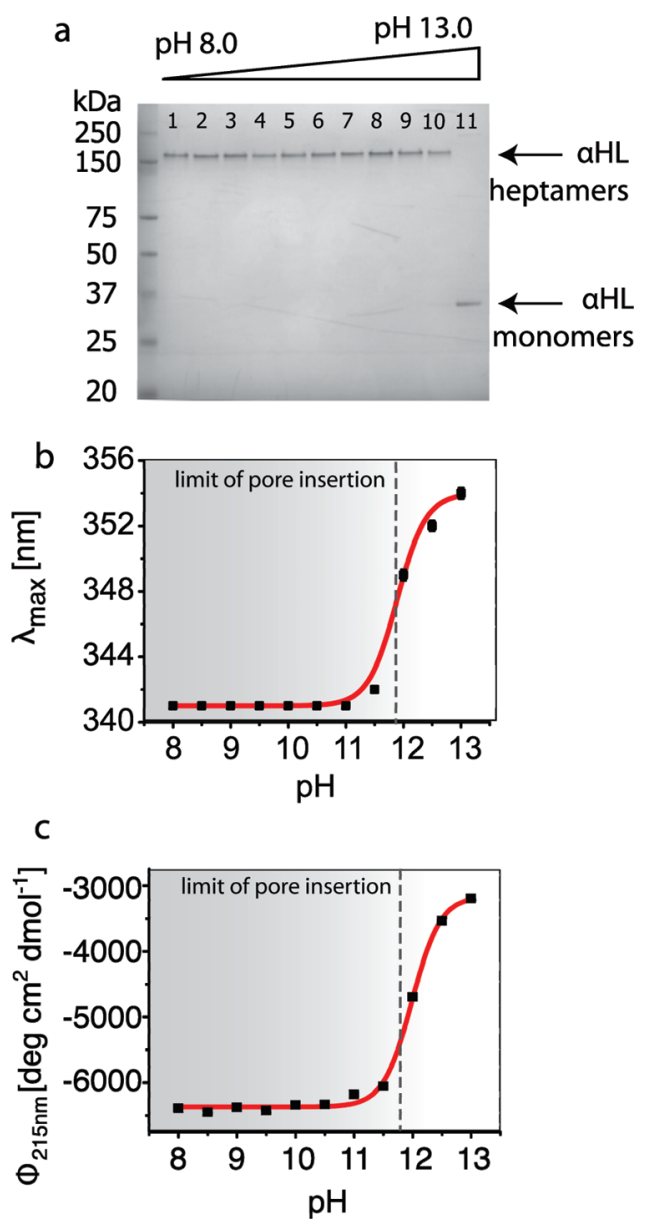

Figure 2. Effect of alkaline $\mathrm{pH}$ on the structure of WT- $\alpha \mathrm{HL}$ heptamers. (a) SDS-polyacrylamide gel electrophoresis (10\%, BisTris gel) of WT- $\alpha \mathrm{HL}$ heptamers $\left(100 \mu \mathrm{g} \mathrm{mL}^{-1}\right)$ preincubated for $8 \mathrm{~h}$ at $\mathrm{pH} 8.0$ (lane 1), $\mathrm{pH} 8.5$ (lane 2), $\mathrm{pH} 9.0$ (lane 3), $\mathrm{pH} 9.5$ (lane 4), pH 10.0 (lane 5) pH 10.5 (lane 6), pH 11.0 (lane 7), pH 11.5 (lane 8), pH 12.0 (lane 9), $\mathrm{pH} 12.5$ (lane 10) and $\mathrm{pH} 13.0$ (lane 11). The positions to which heptameric and monomeric $\alpha \mathrm{HL}$ migrate are marked. (b) $\mathrm{pH}$ dependence of the tryptophan fluorescence emission maximum ( $\lambda_{\max }{ }^{\text {em }}$, excitation at $280 \mathrm{~nm}$ ) of WT$\alpha \mathrm{HL}$ heptamers $\left(100 \mu \mathrm{g} \mathrm{mL}^{-1}\right)$. (c) $\mathrm{pH}$ dependence of the CD signal at $215 \mathrm{~nm}$ for WT- $\alpha$ HL heptamers $\left(100 \mu \mathrm{g} \mathrm{mL}^{-1}\right)$. In (b) and (c), the dashed line indicates the $\mathrm{pH}$ value above which the insertion of $\alpha \mathrm{HL}$ heptamers into a planar lipid bilayer could no longer be observed. The buffer used was $10 \mathrm{mM}$ Tris. $\mathrm{HCl}, 10 \mathrm{mM}$ CAPS, $10 \mathrm{mM} \mathrm{Na}$ phosphate, $150 \mathrm{mM} \mathrm{NaCl}$, containing $0.3 \%$ w/v SDS. Experiments were performed at $20^{\circ} \mathrm{C}$.

of the buried tryptophan residues is completely quenched by nearby residues, all the tryptophans of heptameric $\alpha \mathrm{HL}$ are exposed to the solvent. The $\mathrm{pH}$ dependence of $\lambda_{\max }{ }^{\mathrm{em}}$ of $\alpha \mathrm{HL}$ heptamers were fitted to a sigmoidal function with an inflection point at $\mathrm{pH} 11.9 \pm 0.1$ (Figure $2 b$ ).

Circular dichroism (CD) is used to investigate the secondary structure of proteins. ${ }^{23}$ In $\alpha \mathrm{HL}$, the mass of the cap domain is far greater than that of the stem; therefore, the CD signal is dominated, like the fluorescence emission, by the structure of the cap. In excellent agreement with the fluorescence data, the $\mathrm{pH}$ dependence of the $\mathrm{CD}$ signal measured at $215 \mathrm{~nm}$ was well fitted by a sigmoidal function with a midpoint at $\mathrm{pH} 12.0 \pm 0.1$ (Figures $2 \mathrm{c}$ ). The $\mathrm{CD}$ spectra show that the secondary structure of $\alpha \mathrm{HL}$ heptamers is stable at up to $\mathrm{pH} 11.5$ (Figure S2b, Supporting Information). At $\mathrm{pH} 12.0$ and above, the $\beta$ structure is lost. Interestingly, the insertion of $\alpha \mathrm{HL}$ heptamers into lipid bilayers was greatly reduced above $\mathrm{pH} \sim 11.7$. Therefore, together, the fluorescence and $\mathrm{CD}$ data suggest that the correct folding of the cap is important for the insertion of heptamers.

ssDNA Translocation. At $\mathrm{pH} 8.0$, at positive applied potentials $(V>+60 \mathrm{mV})^{3}$, and at ionic strengths above 0.25 $\mathrm{M},{ }^{24}$ the addition of ssDNA to the cis side of a WT- $\alpha \mathrm{HL}$ pore (or the trans side if the applied potential is reversed) causes blockades (low-amplitude events), in which the ionic current is reduced to a fractional residual current, $I_{\mathrm{R}}$, of zero to 0.15 , arising from the translocation of DNA molecules through the pore. ${ }^{3}$ Not all of the DNA-induced current blockades result from DNA translocation. In the case of the WT pore, for example, a third of the blockades include levels corresponding to $I_{\mathrm{R}} \approx 0.5$. These "mid-amplitude" current levels most likely reflect the transient occupancy of the vestibule by the DNA. ${ }^{25,26}$

In the present work, we found that the translocation of a 92-mer ssDNA (see Supporting Information for DNA sequences) is $\mathrm{pH}$ dependent. In $1.0 \mathrm{M} \mathrm{KCl}$ and at $+120 \mathrm{mV}$, the frequency of ssDNA translocation through the WT- $\alpha \mathrm{HL}$ pore decreased with $\mathrm{pH}$ and it was abolished at $\mathrm{pH}>10.7$ (Figure S4, Supporting Information). This result did not depend on the applied potential $(+120,+150$, and +200 $\mathrm{mV})$, nor on the salt concentration $(1.0,2.0$, and $3.0 \mathrm{M} \mathrm{KCl})$. Although there was a small reduction in the open pore current at alkaline $\mathrm{pH}$ at $+120 \mathrm{mV}$, the striking reduction in the frequency of translocation events was not directly associated with this as the higher voltages $(+150$ and $+200 \mathrm{mV})$ elevated the current to well above the level at $\mathrm{pH} 8.0$ (and $+120 \mathrm{mV}$ ) and translocation was still not observed under alkaline conditions.

Several lines of evidence suggest that the frequency of ssDNA translocation events and the $\mathrm{pH}$ dependence of the ionic current passing through the $\alpha \mathrm{HL}$ pore both depend on the protonation state of lysine residues in the lumen of the pore. First, we have shown here that the structure of the $\alpha \mathrm{HL}$ pore is stable at up to $\mathrm{pH} 11.5$, suggesting that the translocation frequency and the current asymmetry of WT$\alpha \mathrm{HL}$ pores as a function of $\mathrm{pH}$ are not related to the unfolding of the cap. Instead, several lines of evidence suggest that the charge distribution within the lumen modulates ionic flow through the $\alpha H L$ pore. Specifically, comparison of the $\mathrm{pH}$ dependence of the current asymmetry of the WT pore with that of E111N/K147N suggests that the asymmetry in the WT pore depends on the protonation state of the lysine side chains at position 147 at the constriction (see Supporting Information). In addition, a previous study showed that ssDNA translocation depends on the charge distribution within the lumen of the $\alpha \mathrm{HL}$ pore, which can be altered by site-directed mutagenesis. At $\mathrm{pH}$ 8.0 and in $1.0 \mathrm{M} \mathrm{KCl}$, the neutralization of a residue at the cis entrance and a net negative charge at the constriction, in the mutant M113D-RL2, abolished DNA translocation. ${ }^{26}$ The $\mathrm{pH}$ dependence of ssDNA translocation in WT pores is, 
a
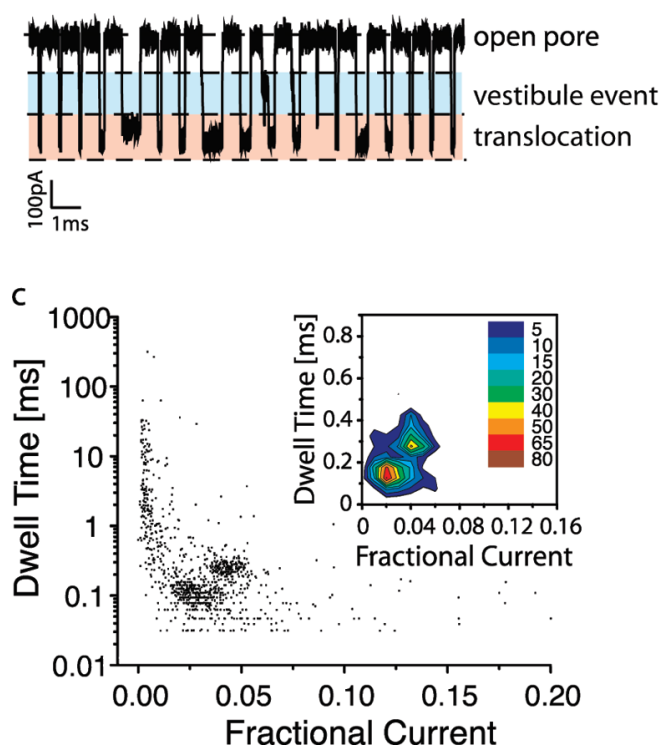

b

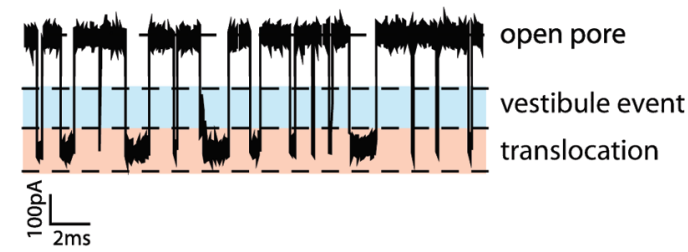

d

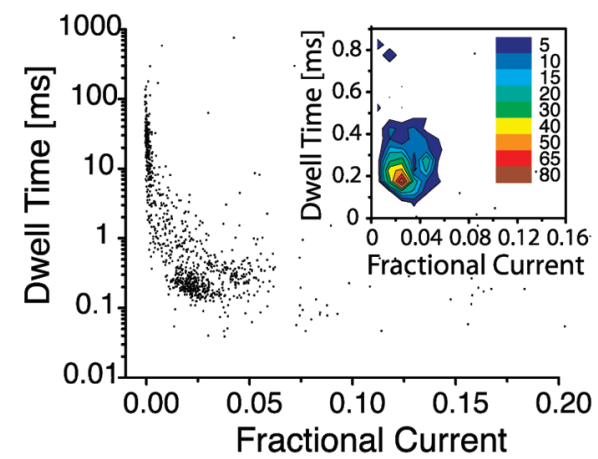

Figure 3. DNA blockades of M113R- $\alpha \mathrm{HL}$ pores at $\mathrm{pH} 11.7$ and $\mathrm{pH}$ 7.6. (a) and (b) Selected traces showing DNA blockades at pH 11.7 and 7.6, respectively. (c) and (d) DNA-induced current blockades displayed as the fraction of the open pore current versus the duration of the current blockade for 1000 events at $\mathrm{pH} 11.7$ and 7.6, respectively. (Insets) Density distribution of the current blockades shorter than 1 ms. The concentration of ssDNA was $2.0 \mu \mathrm{M}$ and the buffer was $10 \mathrm{mM}$ Tris. $\mathrm{HCl}, 10 \mathrm{mM}$ CAPS, $15 \mathrm{mM} \mathrm{K}$ phosphate, $1.0 \mathrm{M} \mathrm{KCl}$ and $100 \mu \mathrm{M}$ EDTA.

therefore, most likely due to the deprotonation of lysine residues, especially Lys-8 and Lys-147.

To induce the translocation of DNA at high $\mathrm{pH}$, we therefore introduced an arginine at the constriction site (M113R), which would remain protonated at high $\mathrm{pH}$, and we increased the ionic strength to $3.0 \mathrm{M} \mathrm{KCl}$ to screen the negatively charged residues within the lumen of the pore. The Arg-113 residues are too close to the translocating DNA to be screened effectively. Under these conditions the addition of $2 \mu \mathrm{M}$ ssDNA into the cis chamber at $\mathrm{pH} 11.7$ produced frequent current blockades attributable to DNA translocation (Figure 3). No translocation events were observed with WT- $\alpha \mathrm{HL}$ pores in $3.0 \mathrm{M} \mathrm{KCl}$.

DNA translocation through M113R pores at alkaline $\mathrm{pH}$ values (Figure 3 ) is similar to DNA translocation at $\mathrm{pH} 8.0$ through WT pores. Notably, we observed vestibule events (midamplitude current levels, Figure 3a) suggesting that the cap domain of $\alpha \mathrm{HL}$ is intact at $\mathrm{pH}$ 11.7. Interestingly, the low-amplitude events, which are due to DNA translocation, are divided in two groups with slightly different fractional residual currents $\left(I_{R}=0.04\right.$ and 0.02 , respectively) and dwell times $(0.13 \pm 0.01 \mathrm{~ms}$ and $0.26 \pm 0.02 \mathrm{~ms}$, respectively $)$ (Figure 3c). These two current levels are not observed at $\mathrm{pH} 8.0$ in $1.0 \mathrm{M} \mathrm{KCl}^{26}$ or at pH 7.6 in $3.0 \mathrm{M} \mathrm{KCl}$ (Figure $3 \mathrm{~d}$ ), and they might involve the translocation of DNA through the M113R $\alpha \mathrm{HL}$ pore led by the $3^{\prime}$ end for one level and the $5^{\prime}$ end for the other. In the WT pore, at $\mathrm{pH} 8.5,3^{\prime}$ translocation and $5^{\prime}$ translocation of poly $(\mathrm{dA})$ have been associated with different residual currents and different probabilities of remaining in the pore at zero applied potential. ${ }^{27-29}$

dsDNA Translocation. The denaturation (strand separation) of dsDNA is routinely accomplished by using alkaline pH. ${ }^{15-17}$ Therefore, if dsDNA were denatured under the high
$\mathrm{pH}$ conditions at which ssDNA is translocated by the M113R- $\alpha$ HL pore, these conditions could be used to investigate the properties of DNA strands with dsDNA as the analyte. Short dsDNA molecules were prepared by annealing complementary synthetic ssDNA molecules. Unhybridized ssDNA was digested by $E$. coli exonuclease I. Three different dsDNA strands were tested with GC contents ranging from 33 to $50 \%$ (see Supporting Information). At pH 7.6 in $3.0 \mathrm{M} \mathrm{KCl}$, the addition of a 60-mer dsDNA $(1 \mu \mathrm{M})$ into the cis chamber at $+150 \mathrm{mV}$, produced a mixture of very long and shorter blockades of WT pores (Figure 4a). The very long current blockades (>10 s) showed fractional residual currents $I_{\mathrm{R}}=0.25$ and in most cases the applied potential had to be reversed to restore the open pore current (vertical arrows in Figure 4a). The shorter current blockades comprised a wide variety of dwell times, ranging from a few milliseconds to a few seconds and residual currents of $I_{\mathrm{R}}=$ 0.05 to 0.4 . While these events were varied in character, in many instances, the blockades were the combination of a long midamplitude event followed by a short low-amplitude event with a residual current between $I_{\mathrm{R}}=0.05$ and 0.15 (Figure 4b). One likely interpretation of these latter current blockades is that dsDNA frequents the vestibule of the pore (midamplitude event), where the electrical potential promotes duplex unzipping and then translocation (low-amplitude event). The unzipping of duplexes (50 nt) has been observed for DNA hairpins with ssDNA overhangs. In accord with our observations, the blockade durations varied from a few milliseconds to a few seconds. ${ }^{30}$ The translocation of bluntended DNA hairpins is also preceded by a long current blockade, which likely corresponds to the presence of the double-stranded stem in the vestibule of the pore before opening of the duplex and translocation. ${ }^{31}$ The residual current level during these events depended on the length of 


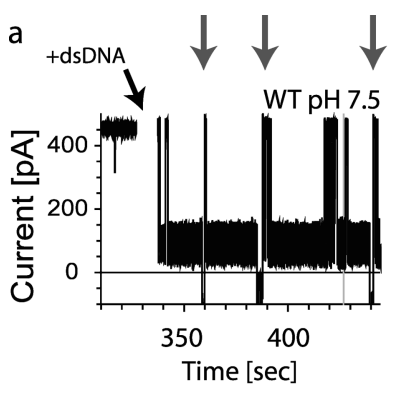

C

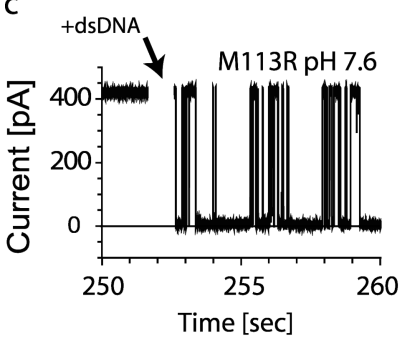

e

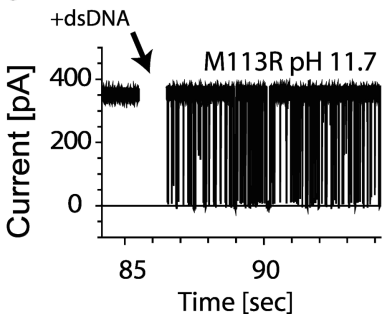

b

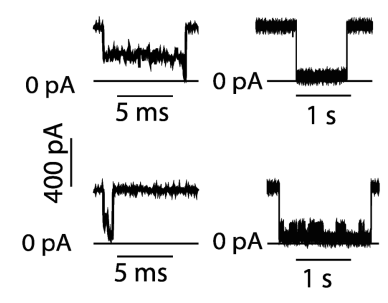

d

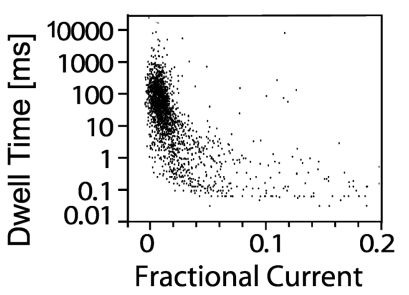

f

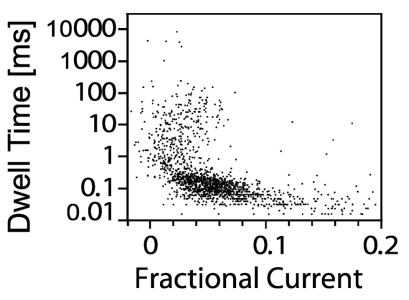

Figure 4. Interaction of dsDNA with WT and M113R- $\alpha$ HL pores. (a) Current blockades observed after the addition of dsDNA (1.0 $\mu \mathrm{M})$ to the cis side of a WT pore at $\mathrm{pH}$ 7.6. The very long current blockades most likely do not correspond to DNA translocation events (see the text). The occluded pore was reopened by ramping the potential to negative and then positive potentials (vertical arrows). (b) Selection of shorter current blockades caused by the interaction of dsDNA with WT nanopores at pH 7.6. (c) Current blockades observed after the addition of dsDNA $(1.0 \mu \mathrm{M})$ to M113R pores at $\mathrm{pH}$ 7.6. The relatively long current blockades (but shorter than the very long events seen with WT- $\alpha \mathrm{HL}$ ) suggest that M113R promotes the unzipping of duplexes. ssDNA then traverses the pore (see the text). (d) Fractional residual current $\left(I_{R}\right)$ versus dwell time of the current blockades for the interaction of dsDNA with M113R nanopores at $\mathrm{pH}$ 7.6. (e) dsDNA-induced blockades through M113R pores at $\mathrm{pH}$ 11.7. The very short current blockades represent direct translocation of ssDNA after denaturation of the dsDNA $(2.0 \mu \mathrm{M})$ at the alkaline $\mathrm{pH}$ of the solution (Figure S5, Supporting Information). (f) Fractional residual current $\left(I_{\mathrm{R}}\right)$ versus dwell time of the current blockades for the interaction of (dissociated) dsDNA with M113R nanopores at $\mathrm{pH}$ 11.7. The buffer was $10 \mathrm{mM}$ Tris. $\mathrm{HCl}$, $10 \mathrm{mM}$ CAPS, $15 \mathrm{mM} \mathrm{K}$ phosphate, $1.0 \mathrm{M} \mathrm{KCl}, 100 \mu \mathrm{M}$ EDTA, $\mathrm{pH}$ 7.6. The $\mathrm{pH}$ in panels e and $\mathrm{f}$ was adjusted to 11.7 by adding small aliquots of $1.0 \mathrm{M} \mathrm{KOH}$ directly to the cis and trans chambers with a pore in the bilayer.

the stem of the hairpin and for the largest, 8-base stem it was $I_{R}=0.35$. By contrast, the very long current blockades found in the present work $\left(I_{\mathrm{R}}=0.25\right)$ may represent dsDNA molecules that enter the vestibule and partially plug the constriction, but fail to translocate through the pore.

The addition of dsDNA to M113R- $\alpha$ HL pores in $3.0 \mathrm{M}$ $\mathrm{KCl}$ at $\mathrm{pH} 7.6$ did not provoke the very long blockades observed with the WT pores under the same conditions, and reversal of the applied potential was not required to restore the open pore current (Figure 4c,d). The current blockades

seen in this case were, like the shorter events seen with the WT pore, spread over a wide range of dwell times. However, no midamplitude events were observed and the $I_{R}$ value during the current blockades was close to zero. Under the same conditions, ssDNA translocation events have an $I_{\mathrm{R}}$ value of 0.04 and the current blockades are described well by a Gaussian distribution with an exponential tail (not shown), which is expected for short ssDNA molecules..$^{32} \mathrm{~A}$ possible explanation of the current blockades of the M113R$\alpha \mathrm{HL}$ pores caused by dsDNA at $\mathrm{pH} 7.6$ is that once in the vestibule the dsDNA interacts with the seven-arginine ring of M113R, which in turn drives the unzipping of the DNA duplex and the translocation of one of the two strands. This interpretation is in keeping with the finding that the mean dwell time decreases with increased positive applied potentials $^{30}$ (data not shown). The presence of the complementary strand of DNA in the vestibule of the pore during translocation of the other strand could explain the lower residual current by comparison with the translocation of ssDNA molecules.

The addition of dsDNA molecules to the cis chamber at $\mathrm{pH}$ values higher than 11.7 produced short current blockades of the M113R- $\alpha \mathrm{HL}$ pore provided that $3.0 \mathrm{M} \mathrm{KCl}$ was present (Figure 4e,f). The blockades were similar to those observed at $\mathrm{pH} 7.6$ with ssDNA ( $I_{\mathrm{R}}$ and $\tau$ values), except that they were not resolved into two distinct peaks as seen with the oligonucleotide used in the ssDNA experiments (Figure 3c) These observations suggest that, at $\mathrm{pH} 11.7$, dsDNA is denatured to form ssDNA, ${ }^{15-17}$ which then enters the pore and is translocated through the barrel. The alkaline denaturation of dsDNA under these conditions was confirmed by measuring the $\mathrm{pH}$ dependence of the absorbance of the DNA at $260 \mathrm{~nm}$ (Figure S5, Supporting Information). ${ }^{16}$

Conclusions. Several studies suggest that single-molecule nanopore sequencing might provide a cheap and fast technology for DNA sequencing. ${ }^{5}$ Notably, a recent paper showed that the four DNA bases in a heteropolymeric DNA strand can be distinguished based on current amplitude when the strand is immobilized within a pore. ${ }^{6}$ There are however several problems that must be solved before sequencing can be achieved with nanopores. The speed at which DNA passes through a pore under an applied potential is too rapid to resolve the different current levels. This difficulty might be overcome by using an enzyme to ratchet ssDNA into the pore. For example, exonuclease I might be attached at the cis entrance of the protein and ssDNA generated on the trans side under alkaline conditions. ssDNA entering the pore with the $3^{\prime}$ end first would be captured by the nuclease and then pulled slowly through the pore as bases are sequentially removed by the enzyme. Nonenzymatic nanopore sequencing might be possible if modification of the lumen of the pore can slow the translocation rate of ssDNA sufficiently. Since, the manipulation of long single-stranded nucleic acids with secondary structure is not trivial, the use of alkaline $\mathrm{pH}$ to denature dsDNA would again be useful under these circumstances. We have shown in this work that $\alpha$ HL nanopores remain functional in the alkaline conditions required to denature dsDNA. Under these conditions, the $\alpha \mathrm{HL}$ pore is 
stable and most likely maintains a folded structure. At alkaline $\mathrm{pH}$, DNA translocation is made possible by using high salt and by using an $\alpha \mathrm{HL}$ mutant with additional positive internal charge.

Acknowledgment. This work was funded by grants from the Medical Research Council, the National Institutes of Health and the European Commission's seventh Framework Programme (FP7) READNA Consortium. M.H. is the recipient of a fellowship from the Merage Foundation.

Supporting Information Available: Additional results, methods, and supporting figures. This material is available free of charge via the Internet at http://pubs.acs.org.

\section{References}

(1) Bayley, H.; Cremer, P. S. Nature 2001, 413, 226-230.

(2) Bayley, H.; Luchian, T.; Shin, S.-H.; Steffensen, M. B. Single-molecule covalent chemistry in a protein nanoreactor. In Single Molecules and Nanotechnology; Rigler, R., Vogel, H., Eds.; Springer: Heidelberg, 2008; pp 251-277.

(3) Kasianowicz, J. J.; Brandin, E.; Branton, D.; Deamer, D. W. Proc. Natl. Acad. Sci. U.S.A. 1996, 93, 13770-13773.

(4) Bayley, H. Curr. Opin. Chem. Biol. 2006, 10, 628-637.

(5) Branton, D.; Deamer, D. W.; Marziali, A.; Bayley, H.; Benner, S. A.; Butler, T.; Di Ventra, M.; Garaj, S.; Hibbs, A.; Huang, X.; Jovanovich, S. B.; Krstic, P. S.; Lindsay, S.; Ling, X. S.; Mastrangelo, C. H.; Meller, A.; Oliver, J. S.; Pershin, Y. V.; Ramsey, J. M.; Riehn, R.; Soni, G. V.; Tabard-Cossa, V.; Wanunu, M.; Wiggin, M.; Schloss, J. A. Nat. Biotechnol. 2008, 26, 1146-1153.

(6) Stoddart, D.; Heron, A.; Mikhailova, E.; Maglia, G.; Bayley, H. Proc. Natl. Acad. Sci. U.S.A. 2009, 106, 7702-7707.

(7) Rhee, M.; Burns, M. A. Trends Biotechnol. 2007, 25 (4), 174-81.

(8) Dekker, C. Nat. Nanotechnol. 2007, 2 (4), 209-15.

(9) Fologea, D.; Gershow, M.; Ledden, B.; McNabb, D. S.; Golovchenko, J. A.; Li, J. Nano Lett. 2005, 5, 1905-1909.

(10) Davenport, M.; Rodriguez, A.; Shea, K. J.; Siwy, Z. S. Nano Lett. 2009, 9 (5), 2125-8.
(11) Tabard-Cossa, V.; Trivedi, D.; Wiggin, M.; Jetha, N. N.; Marziali, A. Nanotechnology 2007, 18, 305505.

(12) Uram, J. D.; Ke, K.; Mayer, M. ACS Nano 2008, 2 (5), 857-72.

(13) Smeets, R. M.; Dekker, N. H.; Dekker, C. Nanotechnology 2009, 20 (9), 95501.

(14) Kang, X.; Gu, L.-Q.; Cheley, S.; Bayley, H. Angew. Chem., Int. Ed. 2005, 44, 1495-1499.

(15) Zimmer, C. Biochim. Biophys. Acta 1968, 161 (2), 584-6.

(16) Ageno, M.; Dore, E.; Frontali, C. Biophys. J. 1969, 9 (11), 1281311.

(17) Chapman, R. E., Jr.; Sturtevant, J. M. Biopolymers 1970, 9 (4), 4457.

(18) Acharya, P.; Cheruku, P.; Chatterjee, S.; Acharya, S.; Chattopadhyaya, J. J. Am. Chem. Soc. 2004, 126 (9), 2862-9.

(19) Vivian, J. T.; Callis, P. R. Biophys. J. 2001, 80 (5), 2093-109.

(20) Eftink, M. R. Methods Biochem. Anal. 1991, 35, 127-205.

(21) Swaminathan, R.; Krishnamoorthy, G.; Periasamy, N. Biophys. J. 1994, 67 (5), 2013-23.

(22) Song, L.; Hobaugh, M. R.; Shustak, C.; Cheley, S.; Bayley, H.; Gouaux, J. E. Science 1996, 274, 1859-1865.

(23) Greenfield, N. J. Nat. Protoc. 2006, 1 (6), 2876-90.

(24) Bonthuis, D. J.; Zhang, J.; Hornblower, B.; Mathe, J.; Shklovskii, B. I.; Meller, A. Phys. Rev. Lett. 2006, 97 (12), 128104.

(25) Butler, T. Z.; Gundlach, J. H.; Troll, M. Biophys. J. 2007, 93 (9), 3229-40.

(26) Maglia, G.; Rincon Restrepo, M.; Mikhailova, E.; Bayley, H. Proc. Natl. Acad. Sci. U.S.A. 2008, 105, 19720-19725.

(27) Wang, H.; Dunning, J. E.; Huang, A. P. H.; Nyamwanda, J. A.; Branton, D. Proc. Natl. Acad. Sci. U.S.A. 2004, 101, 13472-13477.

(28) Mathé, J.; Aksimentiev, A.; Nelson, D. R.; Schulten, K.; Meller, A. Proc. Natl. Acad. Sci. U.S.A. 2005, 102 (35), 12377-82.

(29) Purnell, R. F.; Mehta, K. K.; Schmidt, J. J. Nano Lett. 2008, 8 (9), 3029-34.

(30) Sauer-Budge, A. F.; Nyamwanda, J. A.; Lubensky, D. K.; Branton, D. Phys. Rev. Lett. 2003, 90, 238101-1238101-4.

(31) Vercoutere, W.; Winters-Hilt, S.; Olsen, H.; Deamer, D.; Haussler, D.; Akeson, M. Nat. Biotechnol. 2001, 19, 248-252.

(32) Meller, A.; Nivon, L.; Brandin, E.; Golovchenko, J.; Branton, D. Proc. Natl. Acad. Sci. U.S.A. 2000, 97, 1079-1084.

NL9020232 